\title{
Anti-inflammatory Effects of the Methanol Extract of Polytrichum Commune via NF- $\kappa B$ Inactivation in RAW 264.7 Macrophage Cells
}

\author{
Woong Chо, Seung-Jae Park, Ji-Sun Shin, Young-Su Noh, Eu-Jin Cho, \\ Jung-Hwan NAM* and Kyung-Tae LEE ${ }^{\#}$ \\ Department of Pharmaceutical Biochemistry, College of Pharmacy, Kyung-Hee University, Seoul 130-701, Republic of Korea \\ * Highland Agricultural Institute, Rural Development Adminstration, Pyong chang 232-950, Republic of Korea
}

(Received October 20, 2008; Revised November 6, 2008; Accepted November 10, 2008)

\begin{abstract}
Abstarct - As an attempt to search for bioactive natural products exerting anti-inflammatory activity, we evaluated the effects of the methanol extract of Polytrichum commune Hedw (PCM) (Polytrichaceae) on lipopolysaccharide (LPS)-induced nitric oxide (NO), prostaglandin $\mathrm{E}_{2}\left(\mathrm{PGE}_{2}\right)$ and pro-inflammatory cytokines release in murine macrophage cell line RAW 264.7. PCM potently inhibits the production of NO, $\mathrm{PGE}_{2}$, tumor necrosis factor (TNF)- $\alpha$ and interleukin (IL)-6. Consistent with these results, PCM also concentration-dependently inhibited LPS-induced inducible NO synthase (iNOS) and cyclooxygase (COX)-2 at the protein levels, and iNOS, COX-2, TNF- $\alpha$ and IL-6 at the mRNA levels without an appreciable cytotoxic effect on RAW 264.7 macrophage cells. Furthermore, PCM inhibited LPS-induced nuclear factor-kappa B (NF-KB) activation as determined by $\mathrm{NF}-\mathrm{KB}$ reporter gene assay, and this inhibition was associated with a decrease in the nuclear translocation of p65 and p50 NF-kB. Taken together, these results suggest that PCM may play an anti-inflammatory role in LPS-stimulated RAW 264.7 macrophages through the inhibitory regulation of iNOS, COX-2, TNF- $\alpha$ and IL-6 via $\mathrm{NF}-\mathrm{kB}$ inactivation.
\end{abstract}

Keywords: Polytrichum commune, Inducible nitric oxide synthase (iNOS), Cyclooxygenase-2 (COX-2), Nuclear factor- kappa B (NF-kB), Anti-inflammation

\section{INTRODUCTION}

Inflammation is complex systemic and local response by the host immune system to harmful stimuli such as infection and noxious chemicals interacting with the local immune system (Nathan, 2002; Rankin, 2004). The response is usually acute phase, which may progress into chronic inflammation (Burg and Pillinger, 2001; Guo, 2001). It is marked by the accumulation of variety of inflammatory cells and release of several soluble mediators of inflammation such as reactive oxygen species (ROS), lipid mediators, proteases and cytokines (Rankin, 2004; Huerre and Gounon, 1996).

Nitric oxides (NOs) are well known pro-inflammatory mediators (Vane et al., 1994). In mammalian cells, NO is synthesized by three isoforms of NO synthase (NOS); neuronal NOS (nNOS), endothelial NOS (eNOS) and

\section{${ }^{*}$ Corresponding author}

Tel: +82-2-9610860,

E-mail: ktlee@khu.ac.kr inducible NOS (iNOS). Although nNOS and eNOS are constitutively expressed, iNOS is expressed in response to interferon (IFN)- $\gamma$, lipopolysaccharide (LPS) and various pro-inflammatory cytokines (Kim et al., 2007). Despite its beneficial role in host defense, sustained NO production can be deleterious to the host, and has been implicated in the pathogenesis of various inflammatory diseases (Moncadaet al., 1991; Yunet al., 1996).

Prostanoids including prostaglandins (PGs) are lipid mediators that normally act in a paracrine and autocrine manner to coordinate intercellular events stimulated by a circulating hormone (Smith et al., 2000). Cyclooxygase (COX)-1 and -2 convert arachidonic acid, which is hydrolyzed from cell membrane phospholipids by a phospholipase $A_{2}$, to prostaglandin $\mathrm{PGH}_{2}$ (Kang et al., 2007). COX-1 is constitutively expressed in nearly all tissues and provides PGs to maintain physiological functions like cytoprotection of the stomach and the regulation of renal blood flow. In contrast, elevated level of COX-2 expression accounts for the excessive production of inflammatory PGs. Particularly, $\mathrm{PGE}_{2}$ is a major COX-2 product at 
inflammatory sites where it contributes to local blood flow increases, edema formation and pain sensitization (Prescott et al., 2000; Hinz et al., 2002).

Nuclear factor-kappa B (NF-kB) is one of the most important transcription factors and regulates various immediate cellular genes involved in immune and acute phase, inflammatory responses and cell survival such as iNOS, COX-2, tumor necrosis factor (TNF)- $\alpha$ and interleukin (IL)6. NF-KB is located in the cytoplasm of nonstimulated cells by an interaction with inhibitory proteins, such as inhibitors of $\kappa B(\mid \kappa B s)$, but responds to pro-inflammatory stimuli, when $I \kappa B s$ are rapidly phosphrylated and degraded via $I \kappa B$ kinase (IKK) complex, which results in the release of free $\mathrm{NF}-\mathrm{kB}$ dimmers that translocate to the nucleus for the transcription of target genes and induce the transcription of pro-inflammatory mediators, e.g., iNOS, COX-2, TNF- $\alpha$, IL$1 \beta$, IL-6 and IL-8 (Park et al., 2005).

Thus, as a part of our on-going screening program to evaluate the anti-inflammatory potentials of natural compounds for the development of new anti-inflammatory drug, we investigated the in vitro anti-inflammatory activity of the methanol extract of Polytrichum commune (PCM). Recently various physiological active materials of bryophyte have been reported to possess anti-oxidant (Nimptsch and Pflugmacher, 2008), anti-bacterial and anti-inflammatory effects (Ivanova et al., 2007). Bryophyte Polytrichum commune Hedw (Polytrichaceae) ranges widely in Korea; however, no report has been issued on their anti-inflammatory activity or mode of action. Therefore, we investigated the effects of the methanol extract of Polytrichum commune (PCM) on LPSinduced production of pro-inflammatory mediators including NO, PGE 2 , TNF- $\alpha$ and IL- 6 and its mechanism of actions in RAW 264.7 macrophage cell line.

\section{MATERIALS AND METHODS}

\section{Materials}

Polytrichum commune was collected at Saebong Mountain, Pyongchang-Kun, Kangwon-Do, South Korea in June 2007, and stored in the organic analytical laboratory of highland agricultural institute (Sample number: NIHA-004). Dulbecco's modified Eagle's minimum essential medium (DMEM), fetal bovine serum (FBS), penicillin and streptomycin were obtained from Life Technologies Inc. (Grand Island, NY, USA). iNOS, COX-2, p65, p50, PARP and $\beta$-actin monoclonal antibodies, peroxidase conjugated secondary antibodies and chemiluminescence were purchased from Santa Cruz Biotechnology
Inc (Santa Cruz, CA, USA). Enzyme immunoassay (EIA) kit for $\mathrm{PGE}_{2}$, TNF- $\alpha$ and IL-6 was obtained from R\&D Systems (Minneapolis, MN, USA). Luciferase assay kit was purchased from Promega (Madison, CA. USA). COX inhibitor screening assay kit was obtained from Cayman Chemical Company (Ann Arbor, MI, USA). Skim milk and pNF-kB-Luc reporter plasmid was purchased from BD Biosciences (San Jose, CA, USA). iNOS, COX-2, TNF- $\alpha$, IL- 6 and $\beta$-actin oligonucleotide primers were obtained from Bioneer (Seoul, Korea). NS-398 was purchased from Calbiochem ${ }^{\circledR}$ (San Diego, CA, USA). 3-(4,5-dimethylthiazol-2-yl)-2,5-diphenyltetrazolium bromide (MTT), dimethylsulfoxide (DMSO), sulfanilamide, phenylmethylsulfonylfluride (PMSF), dithiothreitol (DTT), L-N6-(1-iminoethyl) lysine (L-NIL), Escherichia coli lipopolysaccharide (LPS) and all other chemicals were obtained from Sigma (St. Louis, MO, USA).

\section{Sample preparation}

The plant material $(300 \mathrm{~g})$ was extracted three times with methanol $(\mathrm{MeOH})$ under reflux. The methanol extract (defined as PCM) and other extracts were filtered and evaporated on an evaporator under reduced pressure to give a solid PCM $(5 \mathrm{~g})$, which was then stored at $20^{\circ} \mathrm{C}$ until required. We obtained 4 compounds from these fractions, which were luteolin, quercetin, astragalin and rutin. PCM was standardized based on the contents of luteolin and rutin using reverse-phase high-performance liquid chromatography (Waters, Milford, MA, USA) equipped with a UV detector. Luteolin and rutin were found in the PCM at levels of $0.36 \%$ and $0.6 \%$, respectively.

\section{Cell culture and sample treatment}

The RAW 264.7 macrophage cell line was obtained from the Korea Cell Line Bank (Seoul, Korea). These cells were grown at $37^{\circ} \mathrm{C}$ in DMEM medium supplemented with $10 \%$ FBS, penicillin (100 units/ml) and streptomycin sulfate $(100 \mu \mathrm{g} / \mathrm{ml})$ in a humidified incubator of $5 \% \mathrm{CO}_{2}$ atmosphere. Cells were incubated with the tested samples at increasing concentrations (25, 50, 100 $\mu \mathrm{g} / \mathrm{ml})$ or positive control, and then stimulated with LPS 1 $\mu \mathrm{g} / \mathrm{ml}$ for the indicated time.

\section{MTT assay for cell viability}

RAW 264.7 macrophage cells viability after $24 \mathrm{hrs}$ of continuous exposure to the PCM was measured with a colorimetric assay based on the ability of mitochondria in viable cells to reduce MTT as described previously (Kim et al., 2007). 


\section{Nitrite determination}

The nitrite accumulated in the culture medium was measured as an indicator of NO production based on the Griess reaction. Briefly, $100 \mu \mathrm{l}$ of cell culture medium (without phenol red) was mixed with an equal volume of Griess reagent [equal volumes of $1 \%(\mathrm{w} / \mathrm{v})$ sulfanilamide in $5 \%(\mathrm{v} / \mathrm{v})$ phosphoric acid and $0.1 \%(\mathrm{w} / \mathrm{v})$ naphtylethylene-diamine- $\mathrm{HCl}$, incubated at room temperature for $10 \mathrm{~min}$, and then absorbed at $540 \mathrm{~nm}$ using a microplate reader. Fresh culture medium was used as a blank in all experiments. The amount of nitrite in the samples was obtained by the means of $\mathrm{NaNO}_{2}$ serial dilution standard curve and the nitrite production was measured.

\section{Determination of PGE 2 , TNF- $\alpha$ and IL- 6 production}

RAW 264.7 cells were pretreated with PCM for $1 \mathrm{hr}$ and then stimulated with LPS $(1 \mu \mathrm{g} / \mathrm{ml})$ for $24 \mathrm{hrs}$. Levels of $\mathrm{PGE}_{2}, \mathrm{TNF}-\alpha$ and IL-6 in the culture media were quantified using EIA kits.

\section{Determination of COX-1 and COX-2 activity}

RAW 264.7 cells were pretreated with PCM for $1 \mathrm{hr}$ and then stimulated with LPS $(1 \mu \mathrm{g} / \mathrm{ml})$ for $24 \mathrm{hrs}$. COX-1 and -2 activities were quantified using EIA kit according to the manufacturer's instructions.

\section{Western blot analysis}

Cellular proteins were extracted from both the control and PCM-treated RAW 264.7 macrophage cells. The cells were collected by centrifugation and washed once with phosphate buffered saline (PBS). Washed cell pellets were resuspended in PRO-PREP (Intron Biotechnology, Seoul, Korea) extraction lysis buffer and then incubated for $15 \mathrm{~min}$ at $4^{\circ} \mathrm{C}$. Cell debris was removed by microcentrifugation, and the supernatants were quickly frozen. The protein concentration was determined using Bio-Rad protein assay reagent according to the manufacturer's instructions. $40 \mu \mathrm{g}$ of cellular protein was electroblotted onto a nitrocellulose membrane following separation on a $10 \%$ SDS-polyacrylamide gel electrophoresis (PAGE). The immunoblot was incubated overnight with blocking solution ( $5 \%$ skim milk) at $4{ }^{\circ} \mathrm{C}$, and then incubated for 4 hrs with a 1:1000 dilution of monoclonal anti-iNOS, antiCOX-2, anti-p65, anti-p50, anti-PARP and anti- $\beta$-actin antibody (Santa Cruz Biotechnology Inc.). Blots were washed twice with Tween 20/Tris-buffered saline (TTBS) and then incubated with a 1:1000 dilution of horseradish peroxidase-conjugated secondary antibody (Santa Cruz Biotechnology Inc.) for $1 \mathrm{hr}$ at room temperature. Blots were again washed three times with TTBS and then developed by enhanced chemiluminescence (Santa Cruz Biotechnology Inc.).

\section{RNA preparation and RT-PCR}

Total cellular RNA was isolated using Easy Blue ${ }^{\circledR}$ kits (Intron Biotechnology.), according to the manufacturer's instructions. RNA $(1 \mu \mathrm{g})$ was reverse-transcribed (RT) from each sample using MuLV reverse transcriptase, 1 $\mathrm{mM}$ dNTP and oligo $\left(\mathrm{dT}_{12-18}\right) 0.5 \mu \mathrm{g} / \mu \mathrm{l}$. PCR analyses were performed on aliquots of the CDNA preparations to detect iNOS, COX-2, TNF- $\alpha$ and IL- 6 (using $\beta$-actin as an internal standard) gene expression using a thermal cycler (Perkin Elmer Cetus, Foster City, CA, USA). Reactions were carried out in a volume of $25 \mu$ l containing (final concentrations) 1 unit of Taq DNA polymerase, $0.2 \mathrm{mM}$ dNTP, $\times 10$ reaction buffer, and 100 pmol of $5^{\prime}$ and $3^{\prime}$ primers. After an initial denaturation for 2 min at $95^{\circ} \mathrm{C}, 27$ amplification cycles were performed for iNOS and TNF- $\alpha$ (1 $\mathrm{min}$ of $95^{\circ} \mathrm{C}$ denaturation, $1 \mathrm{~min}$ of $58^{\circ} \mathrm{C}$ annealing, and 2 min $72^{\circ} \mathrm{C}$ extension); COX-2 and $\beta$-actin (30 sec of $94^{\circ} \mathrm{C}$ denaturation, $30 \mathrm{sec}$ of $60^{\circ} \mathrm{C}$ annealing, and $1 \mathrm{~min}$ $72^{\circ} \mathrm{C}$ extension); IL-6 (30 sec of $94^{\circ} \mathrm{C}$ denaturation, 30 sec of $50^{\circ} \mathrm{C}$ annealing, and $1 \mathrm{~min} 30 \mathrm{sec} 72^{\circ} \mathrm{C}$ extension). PCR primers used in this study are listed below and were purchased from Bioneer (Seoul, Korea): sense strand iNOS, 5'-AATGGCAACATCAGGTCGGCCATCACT3', anti-sense strand iNOS, 5'-GCTGTGTGTCACAGAAGTCTCGAACTC-3'; sense strand COX-2, 5'GGAGAGACTATCAAGATAGT-3', anti-sense strand COX-2, 5'-ATGGTCAGTAGACTTTTACA-3'; sense strand TNF- $\alpha$, 5'ATGAGCACAGAAAGCATGATC-3', anti-sense strand TNF$\alpha, 5$ '-TACAGGCTTGTCACTCGAATT-3'; sence strand IL-6, 5'-GAGGATACCACTCCCAACAGACC-3', anti-sence strand IL-6 5'-AAGTGCATCATCGTTGTTCATACA-3'; sense strand $\beta$-actin, 5'-TCATGAAGTGTGACGTTGACATCCGT-3', antisense strand $\beta$-actin, 5'-CCTAGAAGCATTTGCGGTGCACGATG-3'. After amplification, portions of the PCR reaction products were electrophoresed on $2 \%$ agarose gel and visualized under UV after ethidium bromide staining.

\section{Nuclear extraction}

RAW 264.7 macrophage cells in 100-mm dishes $(5 \times$ $10^{5} \mathrm{cells} / \mathrm{ml}$ ) were preincubated with various concentrations of PCM $(25,50,100 \mu \mathrm{g} / \mathrm{ml})$ and then stimulated with LPS $(1 \mu \mathrm{g} / \mathrm{ml})$ for $1 \mathrm{hr}$. The cells were collected by centrifugation and washed once with PBS. Nuclear extracts were prepared as described previously with slight modification. Cell pellets were resuspended in hypotonic buffer (10 mM HEPES, pH 7.9, $1.5 \mathrm{mM} \mathrm{MgCl} 2,10 \mathrm{mM} \mathrm{KCl}, 0.2$ $\mathrm{mM}$ PMSF, $0.5 \mathrm{mM}$ DTT, $10 \mu \mathrm{g} / \mathrm{ml}$ aprotinin) and incu- 
bated on ice for $15 \mathrm{~min}$. They were then lysed by adding $0.1 \%$ Nonidet P-40 and vortexing vigorously for $10 \mathrm{sec}$. Nuclei were pelleted by centrifugation at $14,000 \mathrm{rpm}$ for 5 min at $4^{\circ} \mathrm{C}$ and resuspended in high salt buffer $(20 \mathrm{mM}$ HEPES, pH 7.9, 25\% glycerol, $400 \mathrm{mM} \mathrm{KCl}, 1.5 \mathrm{mM}$ $\mathrm{MgCl}_{2}, 0.2 \mathrm{mM}$ EDTA, $0.5 \mathrm{mM}$ DTT, $1 \mathrm{mM} \mathrm{NaF}, 1 \mathrm{mM}$ sodium orthovanadate).

\section{Transient transfection and luciferase assay (Reporter gene assay)}

RAW 264.7 macrophage cells were transfected with pNF-kB-Luc reporter plasmid, which is a promoter construct containing multiple NF-KB biding sites driving a luciferase expression vector (BD Biosciences, San Jose, CA, USA), using Lipofectamine 2000 (Invitrogen, Carlsbad, CA, USA) as instructed by the manufacturer's instructions. Cells were incubated for 2 hrs before the addition of $5 \mathrm{ml}$ of DMEM/10\% FBS. After $24 \mathrm{hrs}$ transfection, cells were pretreated with PCM for $1 \mathrm{hr}$ and stimulated with LPS $(1 \mu \mathrm{g} / \mathrm{ml})$. Following $3 \mathrm{hrs}$ of stimulation, cells were lysed and the luciferase activity was determined using the Promega luciferase assay system (Promega, Madison, CA. USA) and luminometer (Perkin Elmer Cetus.). Luciferase activity was normalized versus sample protein concentrations.

\section{Statistical analysis}

Results are expressed as the means \pm S.D. of triplicate experiments. Statistically significant values were compared using ANOVA and Dunnett's post-hoc test, and $p$-values of less than 0.05 were considered statistically significant.

\section{RESULTS}

\section{Effects of PCM on LPS-induced NO production and iNOS expression}

To assess the effect of PCM on LPS-induced NO production in RAW 264.7 macrophage cells, cells were treated with or without PCM for $1 \mathrm{hr}$, and then with LPS $(1 \mu \mathrm{g} / \mathrm{ml})$ for $24 \mathrm{hrs}$. Culture media were harvested, and NO levels were determined using the Griess reaction (Fig. 1A). LPS induced NO production 25-fold more than the control group, and PCM inhibited this NO production in a dose-dependent manner in the range of $6.25-200 \mu \mathrm{g} /$ $\mathrm{ml}$ with an $\mathrm{IC}_{50}$ of $65.15 \mu \mathrm{g} / \mathrm{ml}$ (Fig. 1A). L-N6-(1-iminoethyl) lysine (NIL) was used as a positive control. The cytotoxic effect of PCM was evaluated in RAW 264.7 cells using MTT assays, but no effect on cell viability was observed at the concentrations used and even up to 200
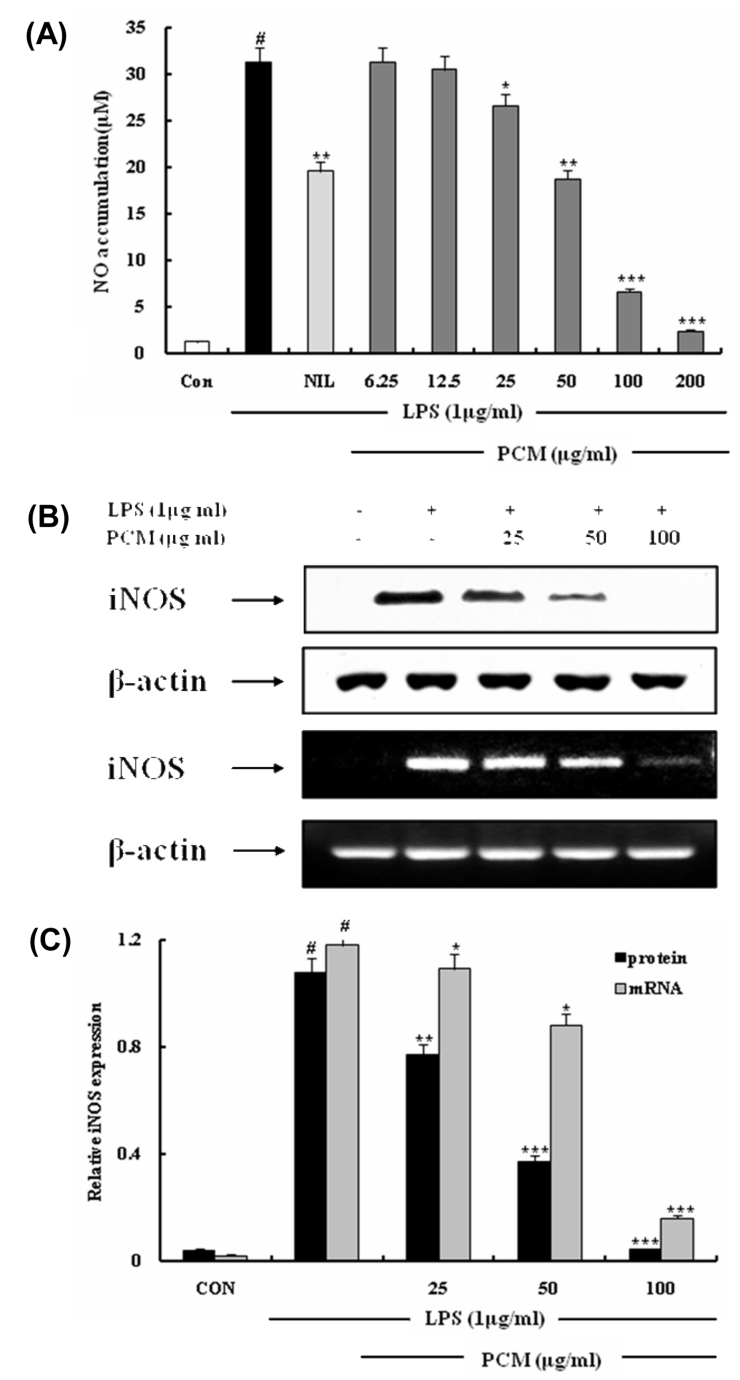

Fig. 1. The effect of PCM on LPS-induced NO production and iNOS protein and mRNA expression in RAW 264.7 macrophage cells. (A) RAW 264.7 macrophage cells were pretreated with PCM $(6.25-200 \mu \mathrm{g} / \mathrm{ml})$ for $1 \mathrm{hr}$ before LPS $(1 \mu \mathrm{g} / \mathrm{ml})$ treatment. Control (Con) values were obtained in the absence of LPS and PCM. L-N ${ }^{6}$ (1-iminoethyl) lysine (L-NIL) was used as a positive control at a concentration of $10 \mu \mathrm{M}$. (B) Cells were treated with different concentrations of PCM $(25,50,100 \mu \mathrm{g} / \mathrm{ml})$ for $1 \mathrm{hr}$, then with LPS (1 $\mu \mathrm{g} / \mathrm{ml})$, and incubated for $24 \mathrm{hrs}$. Total cellular proteins $(40 \mu \mathrm{g})$ were resolved by SDS-PAGE, transferred to nitrocellulose membranes, and detected with specific antibodies, as described in methods. A representative immunoblot of three separate experiments was shown. Total RNA was prepared for the RT-PCR of iNOS gene expression from RAW 264.7 macrophages stimulated with LPS (1 $\mu \mathrm{g} / \mathrm{ml})$ with/without different PCM $(25,50,100 \mu \mathrm{g} / \mathrm{ml})$ for $4 \mathrm{hrs}$. A predicted PCR product of iNOS was obtained as 807 bp by agarose gel electrophoresis.(C) The mRNA and protein levels of iNOS are shown as the the mean \pm S.D. of three independent experiments. ${ }^{\#} p<0.05$ vs. the control group; ${ }^{*} p<0.05$, ${ }^{* *} p<0.01$ and ${ }^{* * \star} \mathrm{p}<0.001$ vs. the LPS-treated group; the significances of the difference between the treated groups was evaluated using the Student's $t$-test. 
(A)

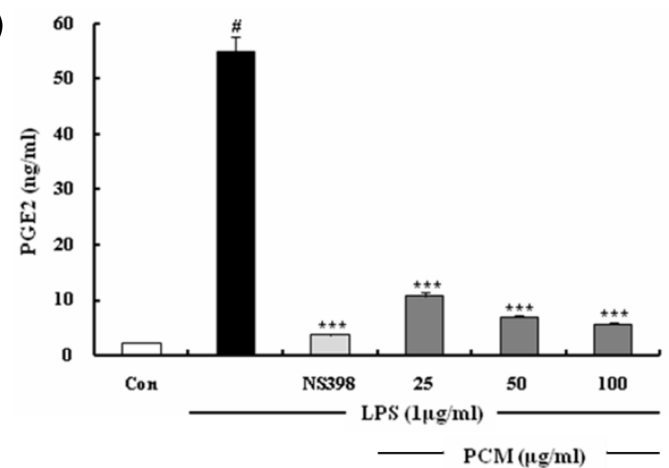

(B)

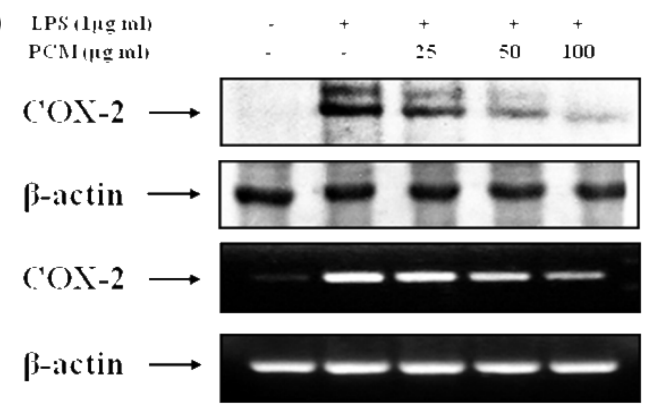

(C)

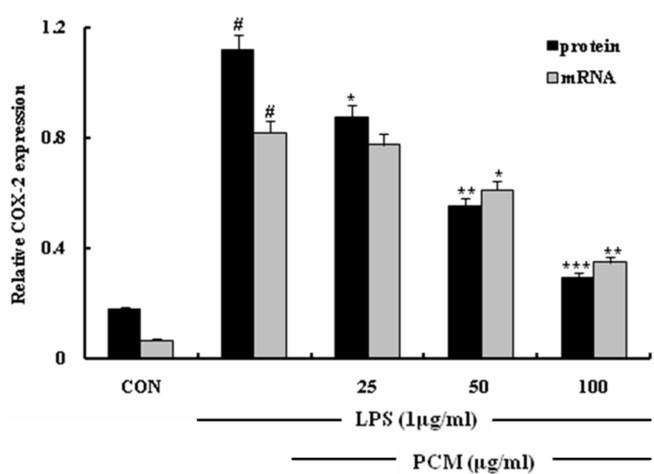

Fig. 2. The effects of $P C M$ on LPS-induced $P G E_{2}$ production $(A)$ and expression of COX-2 protein and mRNA (B) in RAW 264.7 macrophage cells. (A) RAW 264.7 macrophage cells were pretreated with PCM $(25,50,100 \mu \mathrm{g} / \mathrm{ml})$ for $1 \mathrm{hr}$ before LPS $(1 \mu \mathrm{g} / \mathrm{ml})$ treatment. Control (Con) values were obtained in the absence of LPS or tested samples. NS398 was used as an assay positive control at a concentration of $1 \mu \mathrm{M}$. (B) Cells were treated with different concentrations of $\operatorname{PCM}(25,50,100 \mu \mathrm{g} / \mathrm{ml})$ for $1 \mathrm{hr}$, then with LPS $(1 \mu \mathrm{g} / \mathrm{ml})$, and incubated for $24 \mathrm{hrs}$. Total cellular proteins $(40 \mu \mathrm{g})$ were resolved by SDS-PAGE, transferred to nitrocellulose membranes, and detected with specific antibodies, as described in Methods. A representative immunoblot of three separate experiments was shown. Total RNA was prepared for the RT-PCR of COX-2 gene expression from RAW 264.7 macrophages stimulated with LPS $(1 \mu \mathrm{g} / \mathrm{ml})$ with/without different PCM $(25,50,100$ $\mu \mathrm{g} / \mathrm{ml}$ ) for $4 \mathrm{hr}$. A predicted PCR product of iNOS was obtained as 721 bp by agarose gel electrophoresis.(C) The mRNA and protein levels of COX-2 are shown as the the mean \pm S.D. of three independent experiments. ${ }^{*} p<0.05$ vs. the control group; ${ }^{*} p<0.05$, ${ }^{* *} \mathrm{p}<0.01$ and ${ }^{* * *} \mathrm{p}<0.001$ vs. the LPS-treated group; the significances of the difference between the treated groups was evaluated using the Student's $t$-test. $\mu \mathrm{g} / \mathrm{ml}$ (data not shown). Western blot and RT-PCR analyses were performed to determine whether PCM inhibited the mRNA and protein expression of iNOS. In untreated RAW 264.7 macrophage cells, iNOS protein and mRNA were undetectable. However, in response to LPS, the expression of iNOS protein was markedly augmented, and this augmentation was significantly inhibited by PCM in a concentration-dependent manner (Fig. 1B). Moreover, RT-PCR analysis showed that the levels of iNOS mRNA were correlated with its protein level (Figure 1C).

\section{Effects of PCM on LPS-induced $\mathrm{PGE}_{2}$ production and COX-2 expression}

$\mathrm{PGE}_{2}$ production is closely related to pain and inflammation (Vane and Botting, 2003). To determine whether PCM inhibits LPS-induced $\mathrm{PGE}_{2}$ production, cells were pre-incubated with PCM for $1 \mathrm{hr}$, and then activated with LPS for 24 hrs. As shown in Fig. 2A, PCM significantly inhibited the production of $\mathrm{PGE}_{2}$ by $80 \%$ in cells treated $25 \mu \mathrm{g} / \mathrm{ml}$ PCM. NS-398 $(4 \mu \mathrm{M})$ was used as a COX-2 selective inhibitor and showed significant inhibitory effects upon $\mathrm{PGE}_{2}$ production. Densitometric analysis demonstrated that COX-2 protein expression induced by LPS was inhibited by $51 \%$ in cells treated with PCM $50 \mu \mathrm{g} / \mathrm{ml}$ (Fig. 2B). Under the same conditions, the mRNA levels of COX-2 were also significantly decreased after treatment with PCM $(50 \mu \mathrm{g} / \mathrm{ml})$ (Fig. 2C).

\section{Effects of PCM on the activity of COX-1 and COX-2}

To determine the effect of PCM on COX-1 and COX-2 activity, we performed COX inhibitor screening assay according to manufacturer's instructions. PCM significantly inhibited both COX-1 and COX-2 activity as did SC-560 and DuP-697, a positive control for COX-1 and COX-2, respectively (Fig. 3A, 3B).

\section{Effects of PCM on LPS-induced TNF- $\alpha$ and IL- 6 pro- duction and their mRNA expression}

Since PCM was found to inhibit the pro-inflammatory mediators, we further investigated the effect of PCM (25, $50,100 \mu \mathrm{g} / \mathrm{ml}$ ) on LPS-induced TNF- $\alpha$ and IL-6 release and their mRNA expression by EIA and RT-PCR, respectively. Pretreatment of cells with PCM suppressed LPSinduced production and mRNA expression of TNF- $\alpha$ and IL-6 (Fig. 4A, 4B) in a concentration-dependent manner (Fig. 4C).

\section{Effects of PCM on LPS-induced NF- $\mathrm{KB}$ activation and nuclear translocation}

Since the activation of NF-kB is known to mediate 
(A)

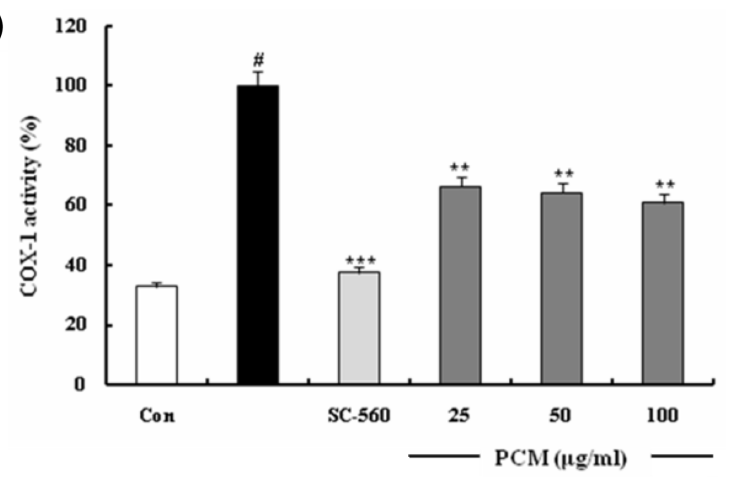

(B)

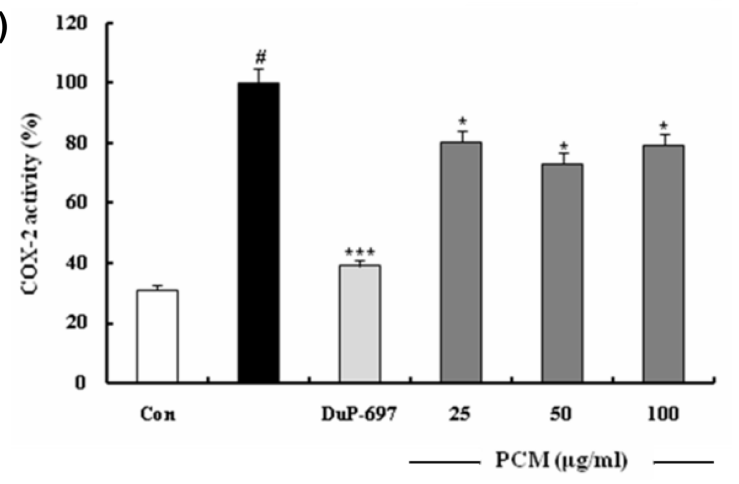

Fig. 3. The inhibitory effect of PCM on LPS-induced COX-1 (A) and COX-2 (B) activity. COX activity was determined by COX inhibitor screening assay kit. COX enzymes (COX-1 and COX-2) were incubated with $\operatorname{PCM}(25,50,100 \mu \mathrm{g} / \mathrm{ml})$ in the presence or absence with selective COX-1 and COX-2 inhibitor (SC-560 and DuP-697, respectively). The COX activity was measured by colorimetric EIA assay using PG screening tracer and antiserum according to the manufacturer's instructions. The values are the mean \pm S.D. of three independent experiments. ${ }^{\#} p<0.05$ vs. the control group; ${ }^{*} p<0.05,{ }^{* *} p<0.01$ and ${ }^{* * *} p<0.001$ vs. the LPS-treated group; the significances of the difference between the treated groups was evaluated using the Student's $t$-test.

LPS-induced expression of iNOS, COX-2, TNF- $\alpha$ and IL6 (Krasnow et al., 1991), luciferase assay was performed to determine whether PCM suppresses NF-kB activation. After 24 hrs transfection with pNF-kB-Luc plasmid, cells were stimulated with $1 \mu \mathrm{g} / \mathrm{ml}$ LPS either in the presence or absence of PCM. PCM significantly suppressed LPS-induced increase in NF-kB-dependent luciferase expression (Fig. 5A).

Since p65 and p50 subunits are reported to be translocated into the nucleus upon the stimulation of LPS in macrophage cells, we performed Western blot analysis to investigate the nuclear levels of p65 and p50 (Fig. 5B). RAW 264.7 macrophage cells were treated with LPS in the presence or absence of PCM for $1 \mathrm{hr}$. Negligible lev-
(A)

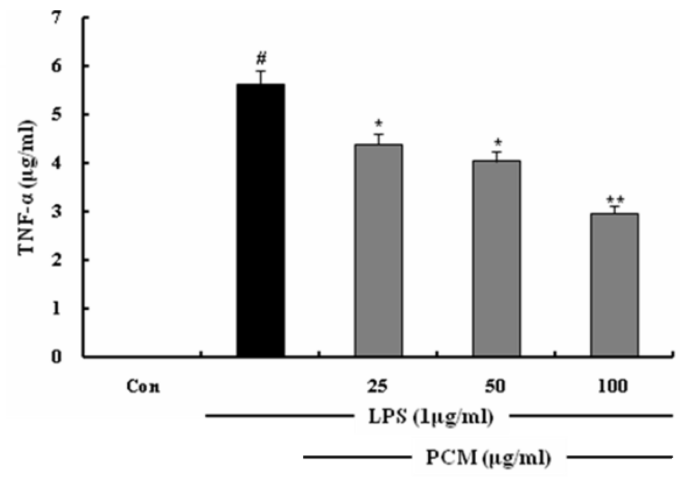

(B)

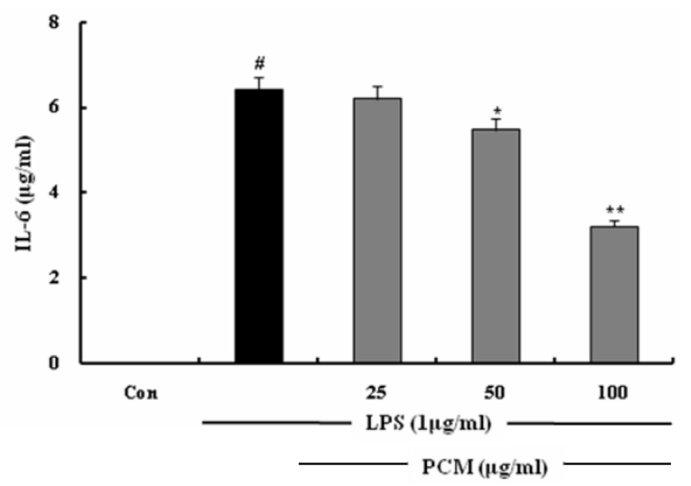

(C)

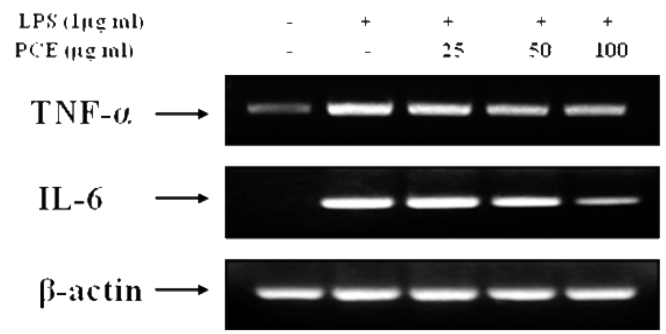

Fig. 4. The effects of PCM on LPS-induced TNF- $\alpha$, and IL-6 release and mRNA expression in RAW 264.7 macrophage cells. (A, B) Cells were treated with different concentrations of $\operatorname{PCM}(25,50,100 \mu \mathrm{g} / \mathrm{ml})$ for $1 \mathrm{hr}$, then with LPS $(1 \mu \mathrm{g} / \mathrm{ml})$, and incubated for $24 \mathrm{hrs}$. Control (Con) values were obtained in the absence of LPS and PCM. The levels of TNF- $\alpha$ and IL- 6 were quantified using EIA kits. The experiment was repeated three times and similar results were obtained. ${ }^{\#} p<0.05$ vs. the control group; ${ }^{*} p<0.05,{ }^{* *} p<0.01$ and ${ }^{* * *} p<0.001$ vs. the LPStreated group; the significances of the difference between the treated groups was evaluated using the Student's $t$-test. (C) Total RNA was prepared for the RT-PCR of TNF- $\alpha$ and IL-6 gene expression from RAW 264.7 macrophages stimulated with LPS $(1 \mu \mathrm{g} / \mathrm{ml})$ with/without different PCM $(25,50,100 \mu \mathrm{g} /$ $\mathrm{ml}$ ) for 4 hr. A predicted PCR product of TNF- á and IL-6 was obtained as 351 and 142bp, respectively, by agarose gel electrophoresis.

els of p65 and p50 protein were detected in the nucleus of untreated cells while treatment with LPS for $1 \mathrm{hr}$ induced a significant translocation of p65 and p50 sub- 
(A)

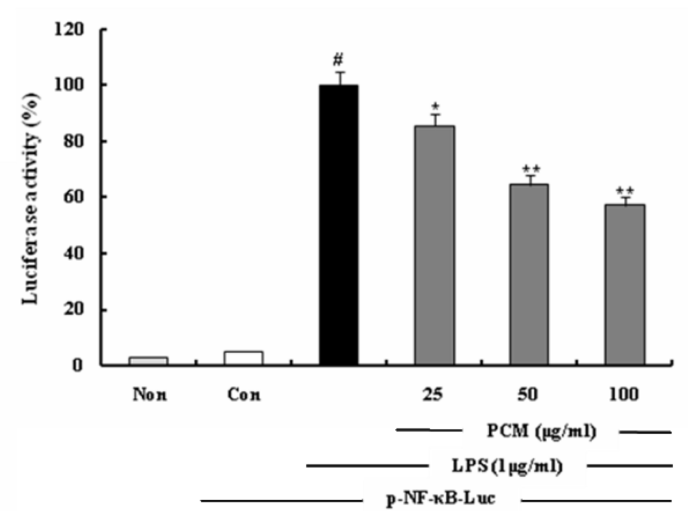

(B)

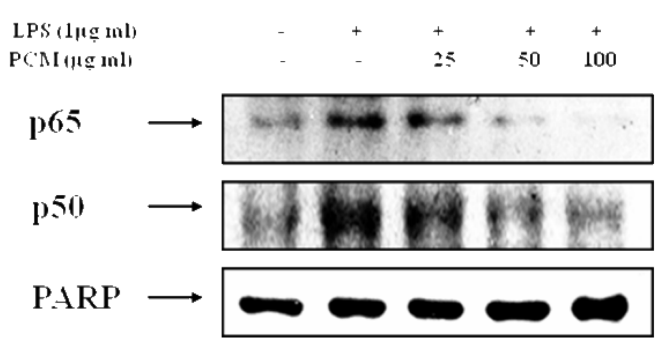

Fig. 5. The inhibitory effect of PCM on NF-KB activation (A) and nuclear translocation (B). (A) Cells were transiently transfected with pNF-KB-Luc reporter and then either left untreated (Con) or were pretreated with $\operatorname{PCM}(25,50,100 \mu \mathrm{g} / \mathrm{ml})$ for 1 hr. LPS $(1 \mu \mathrm{g} / \mathrm{ml})$ was then added and the cells were further incubated for $3 \mathrm{hrs}$. Luciferase activities were determined using a Promega luciferase assay system and a luminometer. The data show the means \pm S.D. of three independent experiments. ${ }^{\#} p<0.05$ vs. the control group; ${ }^{*} p<0.05,{ }^{* *} p<0.01$ and ${ }^{* \star *} p<0.001$ vs. the LPS-treated group. significances of the difference between the treated groups was evaluated using the Student's $t$-test. (B) Cells were pretreated with PCM (25, 50, $100 \mu \mathrm{g} / \mathrm{ml})$ for $1 \mathrm{hr}$ and then with LPS $(1 \mu \mathrm{g} / \mathrm{ml})$ for $1 \mathrm{hr}$. Nuclear extracts $(15 \mu \mathrm{g} / \mathrm{ml})$ were prepared for Western blot analysis to determine the nuclear levels of p65 and p50 NF$k B$. PARP was used as an internal control.

units into the nucleus. Interestingly, PCM markedly inhibited the LPS-induced nuclear translocation of p65 and p50 subunits in RAW 264.7 cells.

\section{DISCUSSION}

Macrophage cells play an important role in the initiation and amplification of a variety of inflammatory disease e.g. septic shock and chronic inflammatory conditions such as asthma, rheumatoid arthritis and Crohn'disease (Gordon S, 2007). LPS stimulates toll-like receptors (TLRs) and triggers cytoplasmic adapter proteins, which results in the phosphorylation and activation of IKK. The IKK- $\beta$ catalytic subunit then phosphorylates the I $\mathrm{kB}-\alpha$ protein, which keeps NF-kB in the cytoplasm of resting cells. Phosphorylation of IKB- $\alpha$ leads to polyubiquitination and subsequent proteasomal degradation (Wang et al. 2001). The activated free NF-кB is translocated into the nucleus where it induces the transcription of genes with an NF-kB consensus site in their promoter region, including iNOS, COX-2 and pro-inflammatory cytokines.

Despite the fact that there have been many efforts to develop anti-inflammatory agents, there is still a large demand for developing new agents. During our continued search for novel anti-inflammatory agents from natural products, we found that the methanol extract of Polytrichum commune Hedw (PCM) potently inhibit LPSinduced $\mathrm{NO}$ and $\mathrm{PGE}_{2}$ production in a concentrationdependent manner. To explore the mechanism of the effects of PCM on LPS-induced inflammation in RAW 264.7 macrophage cells, the protein and mRNA levels of iNOS and COX-2 were examined. PCM suppressed both iNOS and COX-2 mRNA and protein expression in a concentration-dependent manner. Moreover, PCM inhibited LPS-stimulated COX-1 and COX-2 activity. Thus, we postulated that the inhibitory effect of PCM on $\mathrm{PGE}_{2}$ release may be associated with the transcriptional suppressions of COX-2 gene. It is of note that PCM failed to show a dosedependent inhibition on COX-1/-2 activities, indicating nonselective inhibition of COXs by PCM. Considering that COX-1/2 inhibitors are reported to exhibit reversible and time-dependent inhibition of COX enzymes (Esser et al., 2005), further study is necessary to elucidate the exact mechanism of PCM actions in terms of competitiveness, reversibility, and time-dependency for COX inhibition .

It has been reported that cytokines, such as TNF- $\alpha$ and IL-6, are pro-inflammatory mediators in vitro and in vivo (Feldmann et al., 1991). TNF- $\alpha$ elicits a number of physiological effects such as septic shock, inflammation, cachexia and cytotoxicity (Aggarwal et al., 1996). IL-6 is believed to be an endogenous mediator of LPS-induced fever (Dinarello, 2004). PCM significantly reduced LPSinduced TNF- $\alpha$ and IL-6 release in a concentrationdependent manner. RT-PCR analysis showed that the mRNA expression of TNF- $\alpha$ and IL- 6 is correlated with their releases, suggesting that the inhibitory effect of PCM on TNF- $\alpha$ and IL- 6 release may involve the suppression of their mRNA levels.

$\mathrm{NF}-\mathrm{kB}$ is known to play a critical role in the regulation of genes involved in cell survival and to coordinate the expressions of pro-inflammatory enzymes including iNOS, COX-2, TNF- $\alpha$ and IL-6 (Doyle and O'Neill, 2006). In the present study, we have demonstrated that PCM 
significantly inhibited LPS-induced transcriptional activity of NF-KB, consequently resulting in a decrease in the expression of $\mathrm{NO}, \mathrm{PGE}_{2}$ and pro-inflammatory cytokines in RAW 264.7 cells.

The methanol extract of Polytrichum commune (PCM) was further fractionated and it led to the isolation of four flavonoids: luteolin, quercetin, astragalin and rutin. The structures of these compounds were fully elucidated on the basis of ${ }^{1} \mathrm{H}-\mathrm{NMR},{ }^{13} \mathrm{C}-\mathrm{NMR}$ and MS spectrum data and compared with those reported in the literature (Kim et al., 2005; Park et al., 2004; Lee et al., 1994; Hasan et al 1995). Since these compounds have been reported to possess the anti-inflammation effect (Chen et al., 2007; Fang et al., 2008; Inaba et al., 2008), we assume that the anti-inflammatory effects of PCM could be due to these flavonoids. Further pharmacological study on the flavonoids isolated from P. commune will provide more clarified information on the active component.

In summary, these findings suggest that PCM is a potent inhibitor of LPS-induced NO, PGE 2 , TNF- $\alpha$ and IL6 production in RAW 264.7 macrophage cells, and that it appear to act at the transcription level of those genes. Moreover, these inhibitory effects of PCM were found to be associated with NF-kB inactivation. Since NF-KB is a transcription factor that regulates the transcriptions of many inflammation-related genes, its inhibition by PCM may offer a possible approach to the prevention or treatment of severe inflammatory diseases.

\section{ACKNOWLEDGEMENT}

This work was supported by a grant No. R13-2002020-01002-0 from the Korea Science \& Engineering Foundation and by Seoul Research and Business Development Program (10524).

\section{REFERENCES}

Aggarwal, B. B. and Natarajan, K. (1996). Tumor necrosis factors: developments during the last decade. Eur. Cytokine. Netw. 7, 93-124.

Burg, N. D. and Pillinger, M. H. (2001). The neutrophil: function and regulation in innate and humoral immunity. Clin. Immunol. 99, W7-17.

Chen, C. Y., Peng, W.H., Tsai, K. D., and Hsu, S. L. (2007). Luteolin suppresses inflammation-associated gene expression by blocking NF-kappaB and AP-1 activation pathway in mouse alveolar macrophages. Life Sci. 81, 1602-14.

Dinarello, C. A. (2004). Infection, fever, and exogenous and endogenous pyrogens: some concepts have changed. J. Endotoxin. Res. 10, 201-222.

Doyle, S. L. and O'Neill, L. A. (2006). Toll-like receptors: from the discovery of NFkappaB to new insights into transcriptional regulations in innate immunity. Biochem. Pharmacol. 72, 1102-1113.

Esser, R., Berry, C., Du, Z., Dawson, J., Fox, A., Fujimoto, R. A., Haston, W., Kimble, E. F., Koehler, J., Peppard, J., Quadros, E., Quintavalla, J., Toscano, K., Urban, L., van Duzer, J., Zhang, X., Zhou, S. and Marshall, P. J. (2005). Preclinical pharmacology of lumiracoxib: a novel selective inhibitor of cyclooxygenase-2. Br. J. Pharmacol. 144, 538-550.

Fang, S. H., Rao, Y. K. and Tzeng, Y. M. (2008). Anti-oxidant and inflammatory mediator's growth inhibitory effects of compounds isolated from Phyllanthus urinaria. $J$ Ethnopharmacol. 116, 333-340.

Feldmann, M., Brennan, F. M., Chantry, D., Haworth, C., Turner, M., Katsikis, P., Londei, M., Abney, E., Buchan, G., Barrett, K., Corcoran, A., Kissonerghis, M., Zheng, R., Gruberck-Loebenstein, B., Barkley, D., Chu, C. Q., Field, M. and Maini R.N. (1991). Cytokine assays: role in evaluation of the pathogenesis of autoimmunity. Immunol. Rev. 119, 105-123.

Gordon, S. (2007). The macrophage: past, present and future. Eur J Immunol. 37 Suppl 1, S9-17.

Guo, G. J. (2001). Directional migration of leukocytes: their pathological roles in inflammation and strategies for development of anti-inflammatory therapies. Cell. Res. 11, 85-88.

Hasan, A., Ahmed, L., Jay, M. and Voirin, V. (1995). Flavonoid glycosides and anthraquinone from Rumex chulepensis. Phytochemistry 39, 1211-1213.

Hinz, B. and Brune, K. (2002). Cyclooxygenase-2-10 years later. J. Pharmacol. Exp. Ther. 300, 367-375.

lontcheva, I., Amar, S., Zawawi, K.H., Kantarci, A. and Van Dyke, T.E. (2004). Role for moesin in lipopolysaccharide-stimulated signal transduction. Infect. Immun. 72, 2312-2320.

Huerre, M. R. and Gounon, P. (1996). Inflammation: pattern and new concepts. Res. Immunol. 147, 417-434.

Inaba, H., Tagashira, M., Honma, D., Kanda, T., Kou, Y., Ohtake, Y. and Amano, A. (2008). Identification of hop polyphenolic components which inhibit prostaglandin E2 production by gingival epithelial cells stimulated with periodontal pathogen. Biol Pharm Bull. 31, 527-530.

Ivanova, V., Kolarova, M., Aleksieva, K., Dornberger, K. J., Haertl, A., Moellmann, U., Dahse, H. M. and Chipev N. (2007). Sanionins: anti-inflammatory and antibacterial agents with weak cytotoxicity from the Antarctic moss Sanionia georgico-uncinata. Prep. Biochem. Biotechnol. 37, 343-352.

Kang, Y. J., Mbonye, U. R., DeLong, C. J., Wada, M. and Smith, W. L. (2007). Regulation of intracellular cyclooxygenase levels by gene transcription and protein degradation. Prog. Lipid. Res. 46, 108-125.

Kim, J. B., Han, A. R., Park, E. Y., Kim, J. Y., Cho, W., Lee, J., Seo, E. K. and Lee, K.T. (2007). Inhibition of LPS-induced iNOS, COX-2 and cytokines expression by poncirin through the NF-kappaB inactivation in RAW 264.7 macrophage cells. Biol. Pharm. Bull. 30, 2345-2351.

Kim, K. S., Lee, S. H., Kang, K. H. and Kim, B. K. (2005). Flavonoid galactosides from Artemisia apiacea. Nat. Prod. Sci. 11, 10-11.

Krasnow, S. W., Zhang, L. Q., Leung, K. Y., Osborn, L., Kunkel, S. and Nabel, G. J. (1991). Tumor necrosis factor-alpha, inter- 
leukin 1, and phorbol myristate acetate are independent activators of NF-kappa B which differentially activate $T$ cells. Cytokine 3, 372-379.

Lee, M. S., Lim, S. C. and Park, H. J. (1994). Phthalate Ester and Flavonoids Isolated From Leaves of Erythronium japonicum. Kor. J. Medicinal Crop Sci. 2, 67-72.

Moncada, S., Palmer, R. M. and Higgs, E. A. (1991). Nitric oxide: physiology, pathophysiology, and pharmacology. Pharmacol. Rev. 43, 109-142.

Nathan, C. (2002). Points of control in inflammation. Nature 420, 846-852.

Nimptsch, J. and Pflugmacher, S. (2008). Decomposing leaf litter: the effect of allochthonous degradation products on the antioxidant fitness and photosynthesis of Vesicularia dubyana. Ecotoxicol. Environ. Saf. 69, 541-545.

Park, M. H., Song, H. S., Kim, K. H., Son, D. J., Lee, S. H., Yoon, D. Y., Kim, Y., Park, I. Y., Song, S., Hwang, B. Y., Jung, J. K. and Hong, J. T. (2005). Cobrotoxin inhibits NF-kappa B activation and target gene expression through reaction with NF-kappa B signal molecules. Biochemistry 44, 8326-8236

Park, J. C., Park, J. G., Hur, J. S., Choi, M. R., Yoo, E. J., Kim, S. H., Son, J. C. and Kim, M. S. (2004). Inhibitory effects of methanol extract, phenolic acids and favonoids from the leaves of Eucalyptus darylmpleana against 1,1-diphenyl-2picrylhydrazyl radical. Nat. Prod. Sci. 10, 244-247

Prescott, S. M. and Fitzpatrick, F. A. (2000). Cyclooxygenase-2 and carcinogenesis. Biochim. Biophys. Acta. 1470, M69-M78.

Rankin, J. A. (2004). Biological mediators of acute inflammation. AACN. Clin. Issues. 15, 3-17.

Smith, W., DeWitt, D. and Garavito, R. (2000). Cyclooxygenases: structural, cellular, and molecular biology. Annu. Rev. Biochem. 69, 145-182.

Vane, J.R. and Botting R. M. (2003). The mechanism of action of aspirin. Thromb Res. 110, 255-258.

Vane, J. R., Mitchell, J. A., Appleton, I., Tomlinson, A., BishopBailey, D., Croxtall, J. and Willoughby, D. A. (1994). Inducible isoforms of cyclooxygenase and nitric-oxide synthase in inflammation. Proc. Natl. Acad. Sci. USA. 91, 2046-2050

Wang, C., Deng, L., Hong, M., Akkaraju, G. R., Inoue, J. and Chen, Z. J. (2001). TAK1 is a ubiquitin-dependent kinase of MKK and IKK. Nature 412, 346-351.

Yun, H. Y., Dawson, T. T. and Dawson T. M. (1996). Neurobiology of nitric oxide. Crit. Rev. Neurobiol. 10, 291-316. 